\title{
Another fruitful scientific partnership shedding light on the issue of oral health self-care products
}

\author{
Célio Percionoto(a) \\ Sigmar de Mello Rode ${ }^{(b)}$ \\ (a) President of the $\mathrm{SBPqO}$ \\ (b) Scientific Editor
}

$\mathbf{T}$ he $\mathrm{SBPqO}$ is the Brazilian Division of the International Association for Dental Research (IADR). Its mission is to promote the extensive development and dissemination of research that, in all scientific fields, contributes directly to the improvement of oral health.

Today one of our former Presidents, Maria Fidela de Lima Navarro, holds the position of Vice-President of the IADR, and she will be its next president. Another former president of SBPqO, Sigmar de Mello Rode, is currently the President of the Latin American Region (LAR) of the IADR. On a similar note, an IADR Meeting will be held for the first time in Latin America, in the city of Rio de Janeiro, in 2012. This is a result of the significant research presented by Brazilians in international scientific events such as the IADR Annual Meeting, in particular. Achievements of this sort have led Brazil to rank fourth in the world in the publication of scientific papers in the field of dentistry.

In carrying out our mission, one of the goals of this administration has been to establish partnerships with other dental scientific societies. Among these partnerships, those forged with the Brazilian Dental Association $(\mathrm{ABO})$ and the Brazilian Association of Intensive Medicine (AMIB) stand out especially. Other joint ventures include the Brazilian Panel of Oral Health with Johnson \& Johnson's Oral Care, the International Dental Conference of Rio de Janeiro (CIORJ) and the International Dental Conference of São Paulo (CIOSP).

The present supplement to the Brazilian Oral Research Journal is yet another significant partnership established with the Brazilian Association for the Promotion of Oral Health (ABOPREV) to report on the papers and discussions presented at its International Symposium in 2008.

We would like to take this opportunity to invite all members of the dental community to participate in our $26^{\text {th }}$ Annual Meeting, which will take place in Águas de Lindóia, SP, Brazil, from September 9 through 13, 2009.

By acting on these different fronts, we hope to fulfill our mission of promoting, publicizing and encouraging Brazilian dental research. 